\title{
A Suspended Stripline Frequency Tripler Using a Left-Handed Nonlinear Transmission Line
}

\author{
In Bok Kim, ${ }^{1}$ Hongjoon Kim, ${ }^{2}$ Hyun Chul Choi, ${ }^{2}$ and Kang Wook Kim ${ }^{2}$ \\ ${ }^{1}$ LIG Nex1 Co., Ltd., No. 333, Pangyo-ro, Bundang-gu, Seongnam-si, Gyeonggi-do 463-400, Republic of Korea \\ ${ }^{2}$ School of Electronics Engineering, Kyungpook National University, Sankyuk-dong, Buk-gu, Daegu 702-701, Republic of Korea
}

Correspondence should be addressed to Kang Wook Kim; kang_kim@ee.knu.ac.kr

Received 8 August 2014; Accepted 9 December 2014

Academic Editor: Francisco Falcone

Copyright (C) 2015 In Bok Kim et al. This is an open access article distributed under the Creative Commons Attribution License, which permits unrestricted use, distribution, and reproduction in any medium, provided the original work is properly cited.

A suspended stripline frequency tripler using a left-handed nonlinear transmission line (LH NLTL) is presented. The proposed tripler using the LH NLTL is composed of a series of varactor diodes, shunt inductances, and a high-pass filter implemented with suspended stripline (SSL). An ultrawideband microstrip-to-suspended stripline transition is also utilized. The fabricated LH NLTL provides the minimum insertion loss of $1.7 \mathrm{~dB}$ and the maximum insertion loss of $4.7 \mathrm{~dB}$ for a wide frequency band from 2.6 to $18 \mathrm{GHz}$. As a tripler, the measured minimum third harmonic conversion loss is $15.3 \mathrm{~dB}$ at an input frequency of $2.4 \mathrm{GHz}$ and typically $17 \mathrm{~dB}$ from 2 to $3.1 \mathrm{GHz}$.

\section{Introduction}

The frequency multipliers are often used as important components to obtain low phase noise microwave/millimeterwave sources. High frequency signal sources can be obtained by multiplying the low frequency signal. Generally, the frequency multiplier uses either transistors or diodes as a nonlinear element. FET multipliers usually have trade-off between bandwidth and conversion loss [1]. Varactor diodes multipliers are naturally narrowband [2]. However, varactor diode-based frequency multipliers, in general, generate very little noise (phase as well as amplitude noises). The only noise source in this type of multipliers is thermal noise, which comes from the series resistance of the varactor.

Left-handed (LH) media, first postulated by Veselago [3], are becoming an exciting reality, particularly as they are being demonstrated in resonant radio frequency and microwave circuits $[4,5]$. In [6], the authors presented a theoretical investigation of the basic nonlinear wave propagation phenomena in LH media, which is based on the duality of the conventional NLTL, that is, a LH NLTL with anomalous dispersion. They also proved theoretically that the third harmonic generation could be very effective in $\mathrm{LH}$ NLTL. The frequency multipliers based on LH NLTLs are typically compact since the length of the section in practice is determined by the diode package size. These triplers can also be low loss since fewer diodes are required to achieve the same value of conversion efficiency. The authors in [6], however, did not show the actual experimental results. In $[7,8]$, the authors presented the experimental results for the second harmonic generation in a short LH NLTL. Compared to the previous works [6-8], our work shows that the bandwidth of the LH NLTL is extended significantly with an adequate design using 3D simulation and careful fabrication and demonstrates that the third harmonic generation is very effective with LH NLTL.

In this paper, we present a suspended stripline tripler using a left-handed nonlinear transmission line (LH NLTL). The proposed tripler using the LH NLTL is composed of a series of varactor diodes, shunt inductances, and a high-pass filter, which were implemented with suspended striplines. Compared to the earlier literature regarding the triplers [911], our work shows a comparable performance with a smaller size, wider bandwidth, and a simpler structure. And, for the suspended stripline circuit, a suitable and high performing MS-to-SSL (microstrip line to suspended stripline) transition developed by the authors' group [12] has been utilized. 


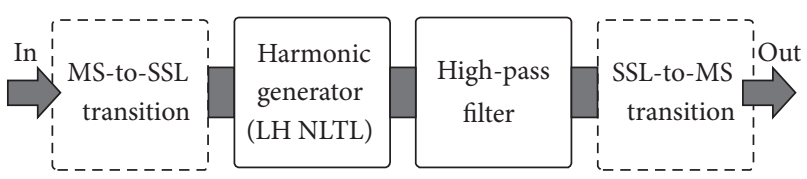

FIGURE 1: Block diagram of the proposed tripler.
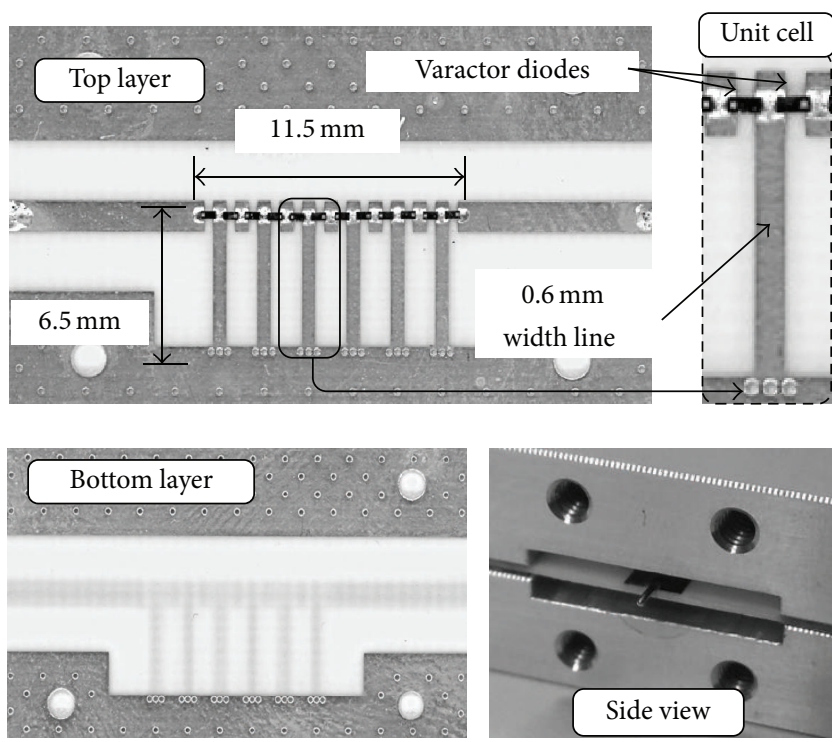

(a)

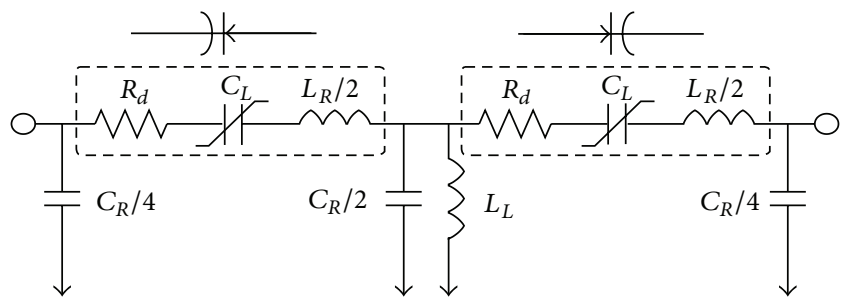

(b)

FIGURE 2: (a) Fabricated third harmonic generator using LH NLTL. (b) Equivalent circuit of a unit cell.

\section{Design of the Balun and Antenna}

The proposed tripler is composed of a harmonic generator, a high-pass filter, and MS-to-SSL transitions as shown in Figure 1. The harmonic generator utilizes nonlinear characteristics of the LH NLTL. The proposed LH NLTL has a simple structure but provides a wide left-handed passband. To effectively remove harmonics, a suspended stripline 5thorder high-pass filter is added. MS-to-SSL transitions are used at the input and output sides to easily integrate with microstrip circuits.

2.1. Third Harmonic Generator Design. Figure 2(a) shows the picture of the proposed suspended stripline third harmonic generator using six-section LH NLTLs. In this paper, for the suspended stripline structures, the circuit was realized on a Rogers RO4003 substrate with $\varepsilon_{r}=3.8$, thickness $h=$
$0.3 \mathrm{~mm}$, and cover height of $h_{c}=0.5 \mathrm{~mm}$. The fabricated harmonic generator circuit is $11.5 \mathrm{~mm}$ by $6.5 \mathrm{~mm}$ in size except for the connectors and extra space for the measurement. A row of $0.6 \mathrm{~mm}$ by $1.4 \mathrm{~mm}$ copper pads separated by $0.2 \mathrm{~mm}$ gaps is formed on the surface of substrate. The twelve varactor diodes (M/A-COM MA46H120 hyperabrupt junction GaAs flip-chip) are attached between these pads. The junction capacitance $\left(C_{j 0}\right)$ of the diodes, from the manufacturer's data sheet, is $1.1 \mathrm{pF}$ with a capacitance ratio of $C(0 \mathrm{~V}) / C$ $(10 \mathrm{~V})=7.5$. The nonlinear capacitance $\left(C_{L}\right)$ in each section is formed by two antiseries diodes. Shunt inductances $\left(L_{L}\right)$ are implemented with a $0.6 \mathrm{~mm}$ wide suspended stripline connecting the pads to the ground plane. The length of these inductive lines is $5.7 \mathrm{~mm}$. The pads on the board surface, together with an inherent parasitic effect $\left(R_{d}\right)$, introduce unavoidable series inductance $\left(L_{R}\right)$ and shunt capacitance $\left(C_{R}\right)$, making the whole circuit a composite right/left-handed transmission line having an equivalent circuit shown in Figure 2(b).

Figure 3 compares the simulated and measured results of the fabricated LH NLTL. The simulation was performed with the CST Microwave Studio. Parameters of the equivalent circuit model in Figure 2(b) were extracted from the $S$-parameters simulated with the Ansys Designer circuit simulator: that is, $C_{L}=1.1 \mathrm{pF}, L_{L}=1.8 \mathrm{nH}, C_{R}=$ $0.4 \mathrm{pF}, L_{R}=0.7 \mathrm{nH}$, and $R_{d}=2.1 \mathrm{Ohm}$. To enhance the bandwidth of the left-handed region and to minimize the parasitic effects, various simulations and experiments were conducted. Also, the number of LH NLTL sections was carefully selected through simulations to maximize device nonlinearity. The bandpass type frequency response with a Bragg cut-off frequency indicates the left-handed nature of the device. The LH high-pass cut-off frequency $f_{c L}$ and the RH low-pass cut-off frequency $f_{c R}$ can be calculated by using (1) and (2), respectively [13]:

$$
\begin{gathered}
f_{c L}=f_{R}\left|1-\sqrt{1+\frac{f_{L}}{f_{R}}}\right|, \\
f_{c R}=f_{R}\left(1+\sqrt{1+\frac{f_{L}}{f_{R}}}\right),
\end{gathered}
$$

where $f_{R}=1 / 2 \pi \sqrt{L_{R} C_{R}}, f_{L}=1 / 2 \pi \sqrt{L_{L} C_{L}}$.

In this paper, $f_{c L}$ is chosen as $2 \mathrm{GHz}$ and $f_{c R}$ as $19 \mathrm{GHz}$. The measured frequency bandwidth of the fabricated $\mathrm{LH}$ NLTL agrees well with the calculated left-handed passband.

2.2. MS-to-SSL Transition Design. We designed the LH NLTL and a filter on suspended stripline because the suspended stripline offers a higher quality factor and wider impedance ranges as compared with other planar transmission lines [13]. To combine the advantages of suspended stripline and microstrip line simultaneously, a suitable and high performing transition structure between the two different transmission lines developed by the authors' group was utilized.

Figure 4 shows the picture of the ultrawideband MS-toSSL transition fabricated in a back-to-back configuration. 


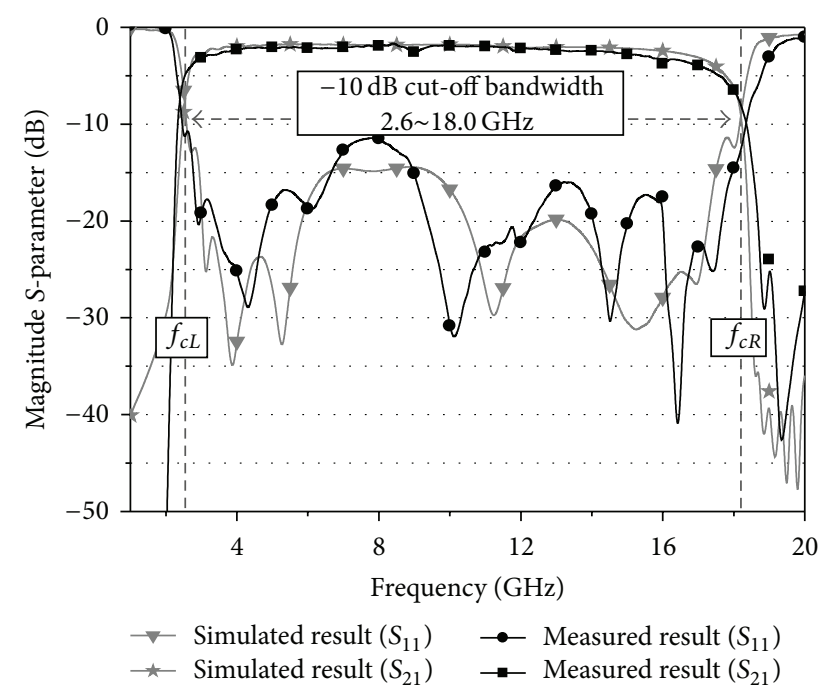

FIGURE 3: Simulated and measured results of the fabricated LH NLTL.
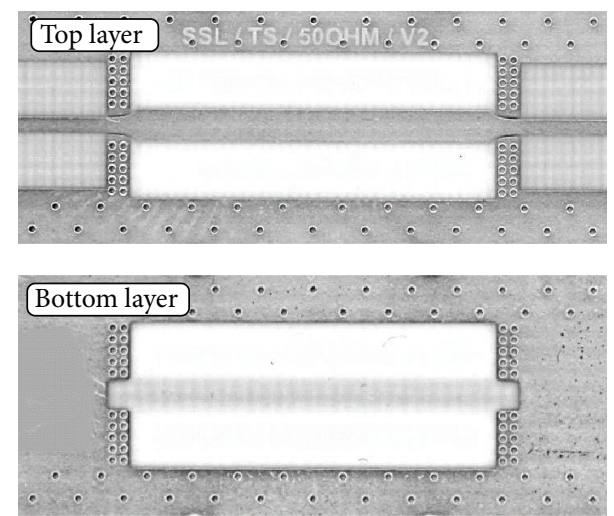

FIGURE 4: Fabricated microstrip-to-suspended stripline transition.

The transition is designed to provide broadband impedance matching and smooth field transformation. Figure 5 compares the simulated and measured results of the transition. It is observed that the transition has less than $1.7 \mathrm{~dB}$ insertion loss and more than $10 \mathrm{~dB}$ return loss for frequencies from $\mathrm{DC}$ to $20 \mathrm{GHz}$. By subtracting the interconnection losses and the transmission line losses, the insertion loss of the implemented transition is estimated to be less than $0.5 \mathrm{~dB}$ per transition for frequencies up to $20 \mathrm{GHz}$.

2.3. High-Pass Filter Design. Figure 6 shows the picture of the fabricated suspended stripline 5th-order high-pass filter [14]. The fabricated high-pass filter is $20 \mathrm{~mm}$ by $3 \mathrm{~mm}$ in size, except for the connectors and extra space, and it has 5th-order Chebyshev response with a $0.5 \mathrm{~dB}$ in-band ripple. Figure 7 compares the simulated and measured results of the proposed filter. The passband is from 5.5 to $15 \mathrm{GHz}$ ( $3 \mathrm{~dB}$ bandwidth). The minimum insertion loss is $0.2 \mathrm{~dB}$. Parameters of the equivalent circuit model were simulated with the Ansys Designer circuit simulator: that is, $C_{1}=0.38 \mathrm{pF}, C_{2}=0.22 \mathrm{pF}$, and $L=1.1 \mathrm{nH}$.

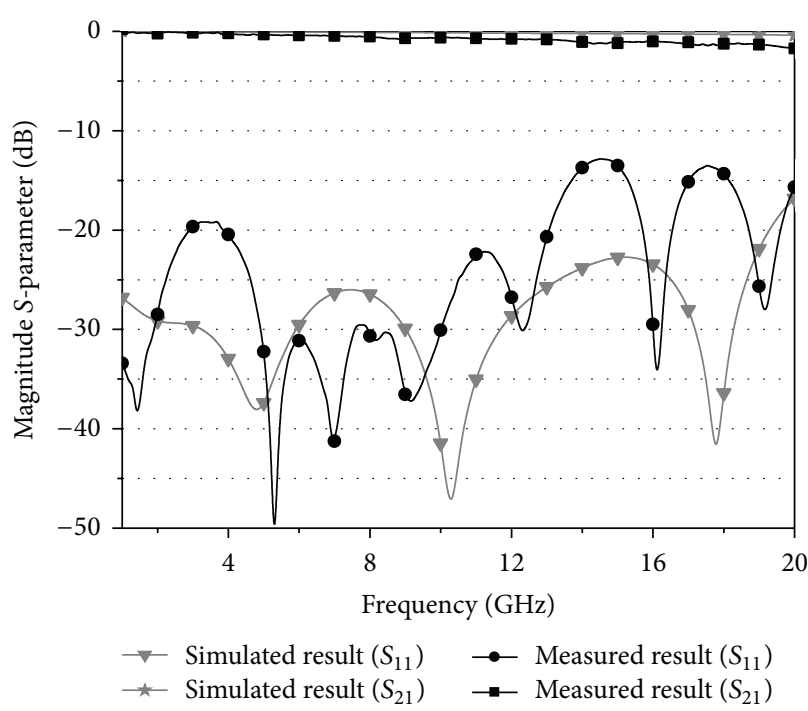

Figure 5: Simulated and measured results of the fabricated transition in a back-to-back configuration with connectors.

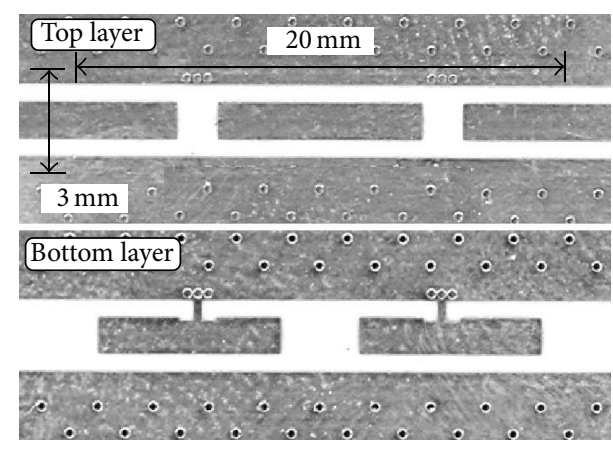

FIGURE 6: Picture of the fabricated high-pass filter.

2.4. Tripler Measurement. Figure 8 shows the picture of the proposed a suspended stripline frequency tripler using sixsection LH NLTLs with a high-pass filter. The fabricated tripler is $30 \mathrm{~mm}$ by $7.5 \mathrm{~mm}$ in size, except for the connectors and extra space.

Figure 9 shows the conversion loss of the 3 rd harmonic component and the suppression levels of the fundamental, 2nd, and 4 th harmonics with $+25 \mathrm{dBm}$ of input power for the frequency range from $2.0 \mathrm{GHz}$ to $3.1 \mathrm{GHz}$. The 3 rd harmonic conversion loss ranges from $15.3 \mathrm{~dB}$ to $19.8 \mathrm{~dB}$ at $+25 \mathrm{dBm}$ of input power. The minimum $3 \mathrm{rd}$ harmonic conversion loss is $15.3 \mathrm{~dB}$ when the input frequency is $2.4 \mathrm{GHz}$. The fundamental frequency suppression level is typically over $50 \mathrm{~dB}$, and 2 nd and 4th harmonics frequency suppression levels are typically $30 \mathrm{~dB}$. The decreased 2 nd harmonic suppression over $2.5 \mathrm{GHz}$ is obtained due to the action of the high-pass filter.

Table 1 compares the performance of the proposed tripler with those in other papers. It can be seen that the proposed LH NLTL-based tripler has wider frequency bandwidth and is smaller in size than other triplers reported in the literature. 
TABLE 1: A performance comparison of frequency tripler.

\begin{tabular}{|c|c|c|c|c|}
\hline Title & Structure & $\begin{array}{l}\text { Frequency band } \\
{[\mathrm{GHz}]}\end{array}$ & $\begin{array}{l}\text { Conversion Loss } \\
{[\mathrm{dB}]}\end{array}$ & Size $[\mathrm{cm}]$ \\
\hline$[9]$ & $\mathrm{LPF}+$ input matching $+\mathrm{HBV}+$ output matching $+\mathrm{BPF}$ & $\begin{array}{l}13.1 \sim 13.9(f o) \\
\text { Pin }=22 \mathrm{dBm}\end{array}$ & $11.2 \sim 17$ & $\begin{array}{c}2 \times 1 \\
\text { Alumina }\end{array}$ \\
\hline$[10]$ & APDP (anti-parallel pair diode) + BPF & $\begin{array}{l}5.72 \sim 6.28(f o) \\
\text { Pin }=22 \mathrm{dBm}\end{array}$ & $16.6 \sim 18.5$ & $\begin{array}{c}5 \times 2 \\
\text { RT5880 }\end{array}$ \\
\hline$[11]$ & $\mathrm{LPF}+$ phase shifters + Schottky diode $+\mathrm{BPF}$ & $\begin{array}{c}7 \sim 9.5(f o) \\
\text { Pin }=22 \mathrm{dBm}\end{array}$ & $17 \sim 20$ & $\begin{array}{c}5 \times 2 \\
\mathrm{RO} 4003\end{array}$ \\
\hline This work & varactor diode + stub + HPF & $\begin{array}{c}2 \sim 3.1(f o) \\
\text { Pin }=25 \mathrm{dBm}\end{array}$ & $15.3 \sim 19.8$ & $\begin{array}{c}3 \times 0.7 \\
\mathrm{RO} 4003\end{array}$ \\
\hline
\end{tabular}

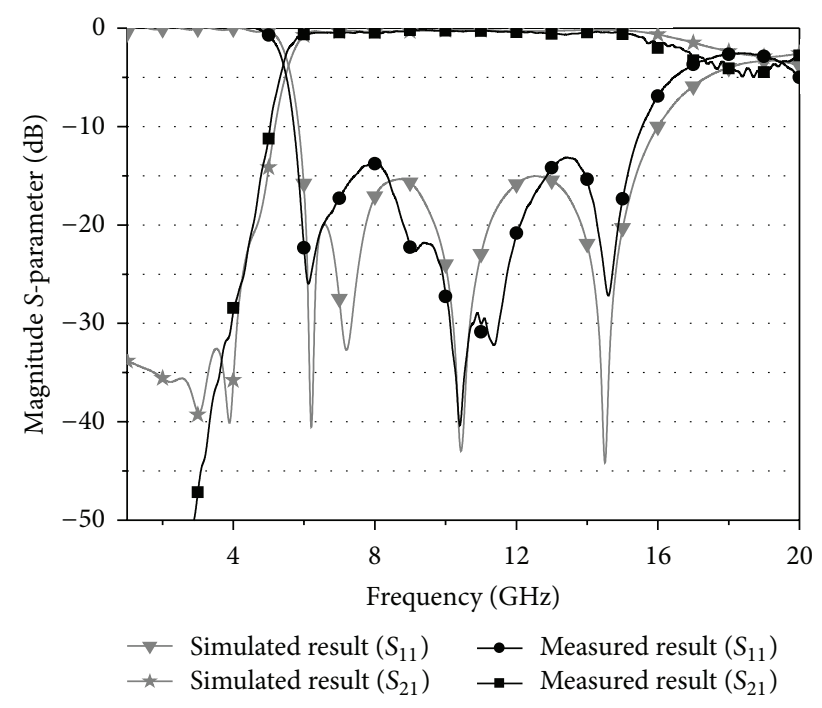

Figure 7: Simulated and measured results of the fabricated highpass filter.

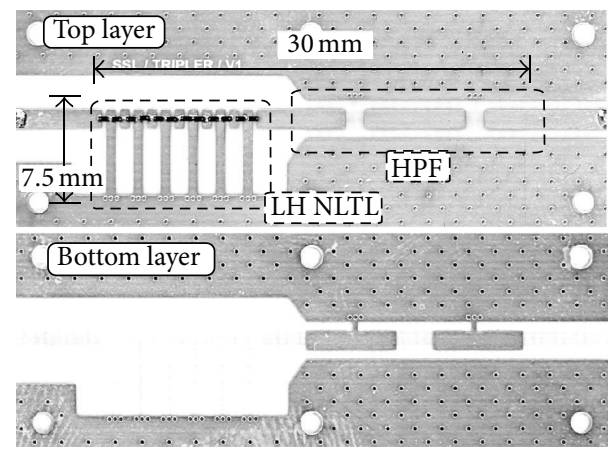

FIgURE 8: Picture of the fabricated tripler.

\section{Conclusion}

In this paper, we present a suspended stripline frequency tripler using a LH NLTL. The proposed tripler exhibits broader frequency bandwidth in a smaller size with comparable performance compared with the previously reported research results. The fabricated LH NLTL has a wide lefthanded passband from $2.6 \mathrm{GHz}$ to $18 \mathrm{GHz}$. The measured

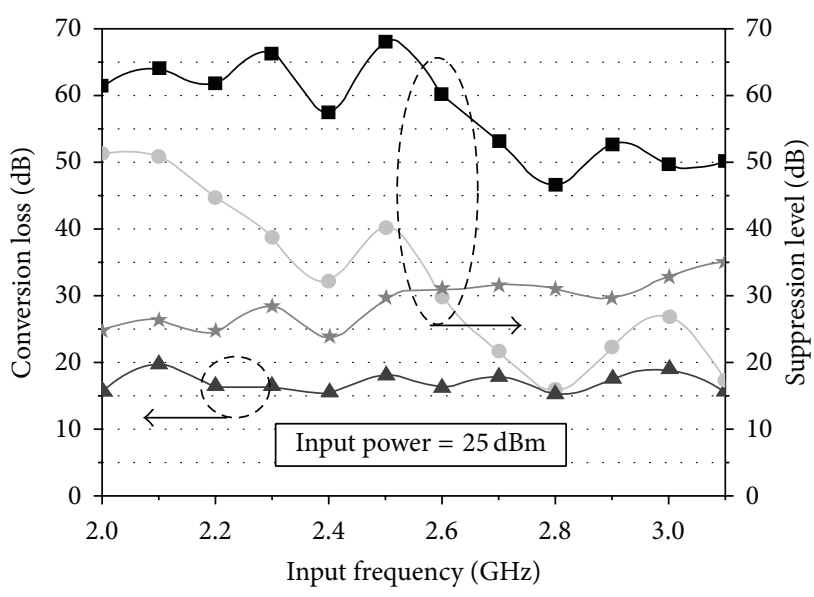

$\rightarrow$ Fundamental suppression $\rightarrow$ 3rd harmonic conversion loss
$\rightarrow-$ 2nd harmonic suppression $\quad \star$ 4th harmonic suppression

FIGURE 9: Third harmonic conversion loss and the suppression levels of the fundamental, $2 \mathrm{nd}$, and 4 th harmonics with $+25 \mathrm{dBm}$ of input power.

third harmonic conversion loss was typically $17 \mathrm{~dB}$ at an input frequency range from $2 \mathrm{GHz}$ to $3.1 \mathrm{GHz}$. An ultrawideband microstrip-to-suspended stripline transition was used to easily integrate with microstrip-based circuits.

\section{Conflict of Interests}

The authors declare that there is no conflict of interests regarding the publication of this paper.

\section{Acknowledgment}

This work is supported by NRF Korea under Grant no. NRF2012-M1A7A1A02034753.

\section{References}

[1] A. M. Pavio, S. D. Bingham, R. H. Halladay, and C. A. Sapashe, "A Distributed broadband monolithic frequency multiplier," in Proceedings of the IEEE MTT-S International Microwave Symposium Digest, pp. 503-504, 1988. 
[2] S. A. Mass and Y. Ryu, "A broadband, planar, monolithic resistive frequency doubler," in Proceedings of the IEEE Microwave and Millimeter-Wave Monolithic Circuits Symposium, pp. 175178, San Diego, Calif, USA, May 1944.

[3] V. G. Veselago, "The electrodynamics of substances with simultaneously negative values of $\varepsilon$ and $\mu$," Soviet Physics Uspekhi, vol. 10, no. 4, pp. 509-514, 1968.

[4] R. A. Shelby, D. R. Smith, and S. Schultz, "Experimental verification of a negative index of refraction," Science, vol. 292, no. 5514, pp. 77-79, 2001.

[5] A. Lai, C. Caloz, and T. Itoh, "Composite right/left-handed transmission line metamaterials," IEEE Microwave Magazine, vol. 5, no. 3, pp. 34-50, 2004.

[6] A. B. Kozyrev and D. W. van der Weide, "Nonlinear wave propagation phenomena in left-handed transmission-line media," IEEE Transactions on Microwave Theory and Techniques, vol. 53, no. 1, pp. 238-245, 2005.

[7] A. B. Kozyrev, H. Kim, A. Karbassi, and D. W. van der Weide, "Wave propagation in nonlinear left-handed transmission line media," Applied Physics Letters, vol. 87, no. 12, Article ID 121109, 2005.

[8] H. Kim, A. B. Kozyrev, A. Karbassi, and D. W. van der Weide, "Compact left-handed transmission line as a linear phasevoltage modulator and efficient harmonic generator," IEEE Transactions on Microwave Theory and Techniques, vol. 55, no. 3, pp. 571-578, 2007.

[9] K. Krishnamurthi, E. Boch, and R. G. Harrison, "A Ka-band planar tripler based on a stacked symmetric InP heterostructurebarrier varactor," in Proceedings of the IEEE MTT-S International Microwave Symposium Digest, vol. 2, pp. 549-552, 1995.

[10] J. Min, S. Cho, H. Kim et al., "Design for frequency tripler using novel band-pass filter with low insertion loss," The Journal of The Korean Institute of Communication Sciences, vol. 31, no. 10A, pp. 1031-1036, 2006.

[11] C. Baer and T. Musch, "A passive 8 to $24 \mathrm{GHz}$ frequency tripler based on microstrip line circuits and schottky diodes," in Proceedings of the Asia-Pacific Microwave Conference Proceedings (APMC '10), pp. 164-167, Yokohama, Japan, December 2010.

[12] Y.-G. Kim and K. W. Kim, "A new design method for ultrawideband microstrip-to-suspended stripline transitions," International Journal of Antennas and Propagation, vol. 2013, Article ID 801950, 9 pages, 2013.

[13] C. Caloz and T. Itoh, Electromagnetic Metamaterials: Transmission Line Theory and Microwave Applications: The Engineering Approach, John Wiley \& Sons, Hoboken, NJ, USA, 2006.

[14] X.-J. Liao, W.-H. Hsu, and M.-H. Ho, "Design of the UWB bandpass filter with a notch response using the suspended stripline," in Asia Pacific Microwave Conference (APMC '09), pp. 902-904, Singapore, 2009. 

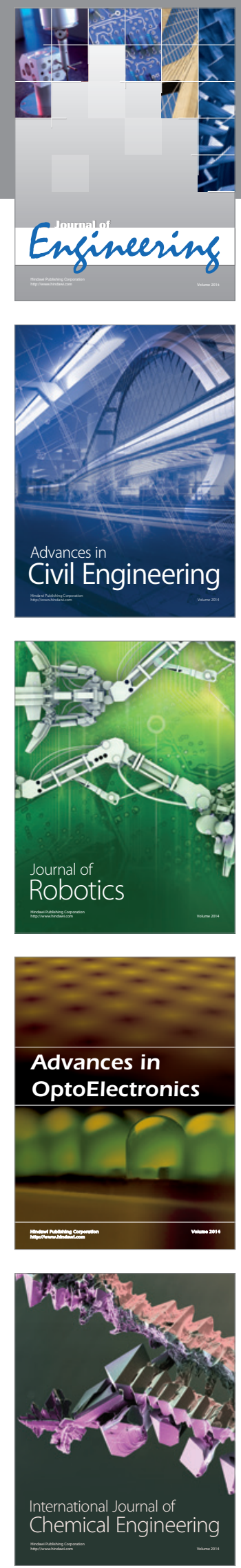

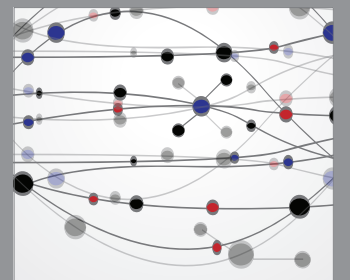

The Scientific World Journal
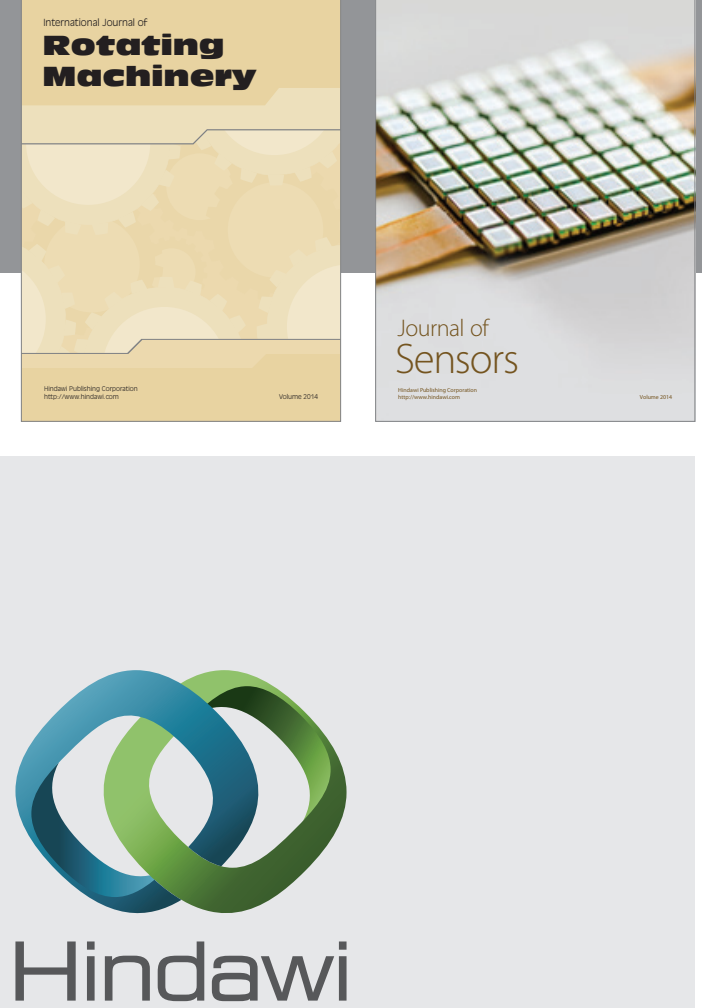

Submit your manuscripts at http://www.hindawi.com
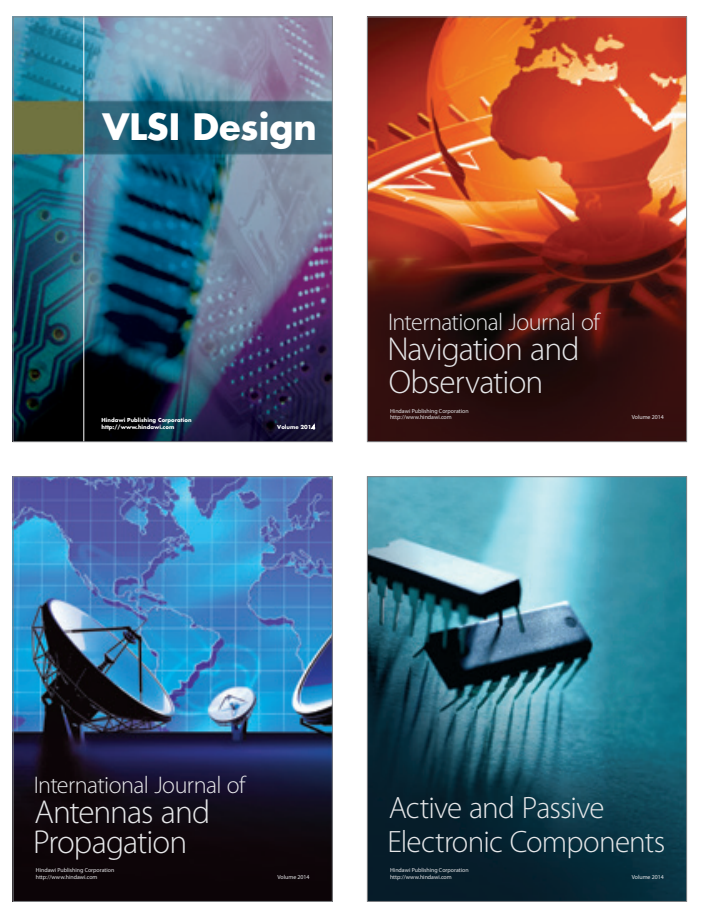
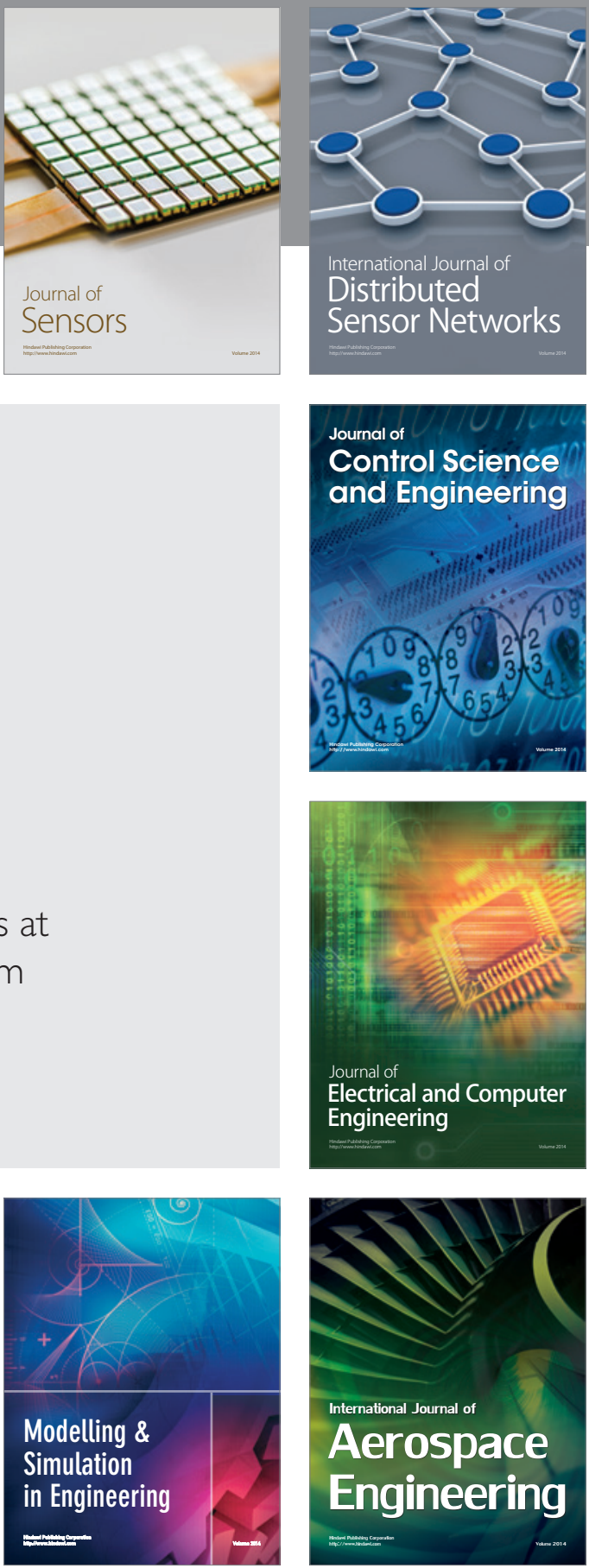

Journal of

Control Science

and Engineering
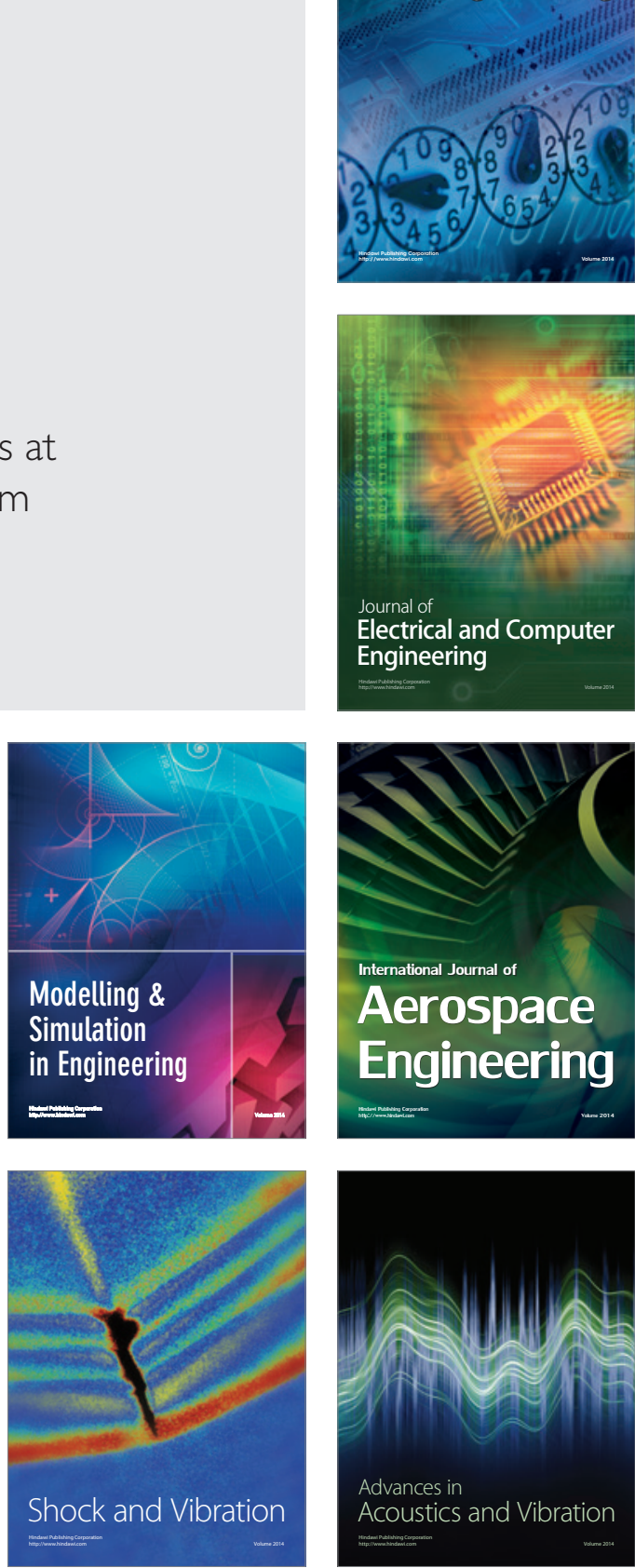